\title{
Arbitrary Fluorescence Units
}

National Cancer Institute

\section{Source}

National Cancer Institute. Arbitrary Fluorescence Units. NCI Thesaurus. Code C77534.

Arbitrary unit(s) of fluorescent luminescence. 